\title{
COMPARATIVE DATA REVIEW ON PREVALENCE, ECONOMIC BURDEN AND EPIDEMIOLOGY OF ALLERGIC RHINITIS BETWEEN THE USA AND INDIA
}

\author{
Muntajibuddin Arif Ahmed ${ }^{1}$ \\ ${ }^{1}$ Associate Professor, Department of Paediatrics, Shadan Medical College, Hyderabad.
}

ABSTRACT
BACKGROUND
The prevalence of allergic diseases such as Allergic Rhinitis (AR) and asthma is markedly increasing worldwide as societies adopt
western lifestyles. An estimated 300 million people worldwide have asthma, about $50 \%$ of whom live in developing countries and
about 500 million people suffer from AR. The US is the largest developed country in the world and India is the second most populous
country. Although, it is a third world country, it has a middle class population equivalent to that of US.

\section{METHODS}

A review of the comparative data on prevalence, economic burden and epidemiology of Allergic Rhinitis was done along with the comparison on available health care and professional services.

\section{RESULTS}

The data studied showed a gigantic difference in the expenditure and available health care between the US and India. The total direct ( $\$ 7.3$ billion) and indirect costs ( $\$ 4.28$ billion, including loss of productivity) estimated in the United States for 2002 were $\$ 11.58$ billion. This pales into insignificance the Indian Government current health expenditure of \$5.9 million. Allergic rhinitis affects between $10 \%$ and $30 \%$ of all adults and as many as $40 \%$ of children 1 . In India, Allergic Rhinitis (AR) is considered to be a trivial disease, despite the fact that symptoms of rhinitis were present in $75 \%$ of children and $80 \%$ of asthmatic adults. The ISAAC phase one data from India revealed that nasal symptoms alone were present in $12.5 \%$ children in the 6-7 years' age group and $18.6 \%$ in the 13-14 years' age group. In India we spend almost 1000 crores on medications each year. Besides, there is a huge difference in the available specialists in the two countries.

\section{CONCLUSIONS}

The quantum difference in the expenditure and available health care for AR in US raises questions whether the US is overspending on disease causing mainly morbidity. However, the data revealed that a vast number of patients in India with AR are under diagnosed and are suffering not only from the complications of the disease, but also have a poor Quality Of Life (QOL), Mitigation of which is the primary goal of therapy of AR.

\section{KEYWORDS}

Health Economics, Allergic Rhinitis.

HOW TO CITE THIS ARTICLE: Ahmed MA. Comparative data review on prevalence, economic burden and epidemiology of allergic rhinitis between the USA and India. J. Evolution Med. Dent. Sci. 2016;5(45):2840-2842, DOI: 10.14260/jemds/2016/663

\section{INTRODUCTION}

The prevalence of allergic diseases such as Allergic Rhinitis (AR) and asthma is markedly increasing worldwide as societies adapt to western lifestyles. The allergic diseases seriously impair the Quality of Life (QOL). The burden caused by impairment of QOL due to the allergic diseases can be approximately gauged by the prevalence of allergic rhinitis: South Asia itself accounts for 100 million cases out of the global total of 500 million people suffering with allergic rhinitis. ${ }^{1}$ (Figure 1) The US is the largest economically developed country in the world and India is the second most populous country. Unlike the USA, it is a third world country but India's middle class population is equivalent to that of the USA; ${ }^{2}$ (Figure 2) and allergies are more to do with western style of living. ${ }^{3}$

Financial or Other, Competing Interest: None.

Submission 16-02-2016, Peer Review 22-04-2016,

Acceptance 29-04-2016, Published 06-06-2016.

Corresponding Author:

Dr. Muntajibuddin Arif Ahmed,

Masha Medical Centre,

11-4-637/1, A.C. Guard

Hyderabad-500004.

E-mail: arifahmed1960@gmail.com

DOI: $10.14260 /$ jemds/2016/663
In the US, the total annual expenditure on the management of allergic rhinitis is about 5.5 billion dollars annually, which is far ahead of India. In India, we have no approved courses on Allergy.

\section{METHODS}

A review of the comparative data between the USA and India on prevalence, economic burden and epidemiology of Allergic Rhinitis was done along with the comparison on available health care and professional services. These were collected from various published medical indexed journals, economic data reports and from standard teaching modules.

The comparison was done on the population both total and middle class. The epidemiology and prevalence was compared as per the ISAAC study. The economic burden was taken from the direct expenditure on drugs, medications, consultation fees and on diagnostics in the USA. In India we had only the data of the total sales of Allergy and Asthma medications. The teaching programs were calculated from the residency programs in USA and from MCI data base in India.

\section{RESULTS}

The data studied showed a gigantic difference in the expenditure and available health care between the US and India.

The total direct ( $\$ 7.3$ billion) and indirect costs $(\$ 4.28$ billion, which includes loss of productivity) estimated in the 
United States for 2002 were $\$ 11.58 .^{4}$ an amount which is equivalent to the Indian Government current health expenditure of $\$ 5.9$ million per year. And one realizes how insignificant the Indian expenditure is especially when Allergic rhinitis affects between $10 \%$ and $30 \%$ of all adults and as many as $40 \%$ of children 1 . In India, Allergic Rhinitis (AR) is considered to be a trivial disease, despite a report indicating that symptoms of rhinitis are present in $75 \%$ of children and $80 \%$ of asthmatic adults. ${ }^{5}$ The International Study of Asthma and Allergy in Childhood (ISAAC) phase I data from India revealed that nasal symptoms alone were present in $12.5 \%$ children in the 6-7 years' age group and $18.6 \%$ in the $13-14$ years' age group. ${ }^{6}$ In India we spend almost $\$ 160$ million each year on medications of asthma and allergy. ${ }^{7}$ Besides, this low budget for allergic diseases, we find that there is a huge difference in the available specialists in the two countries specialized in allergic diseases. The charts shown below describe well the differences between the two countries of the prevalence of disease, population, economy, expenditure and education in allergic diseases.
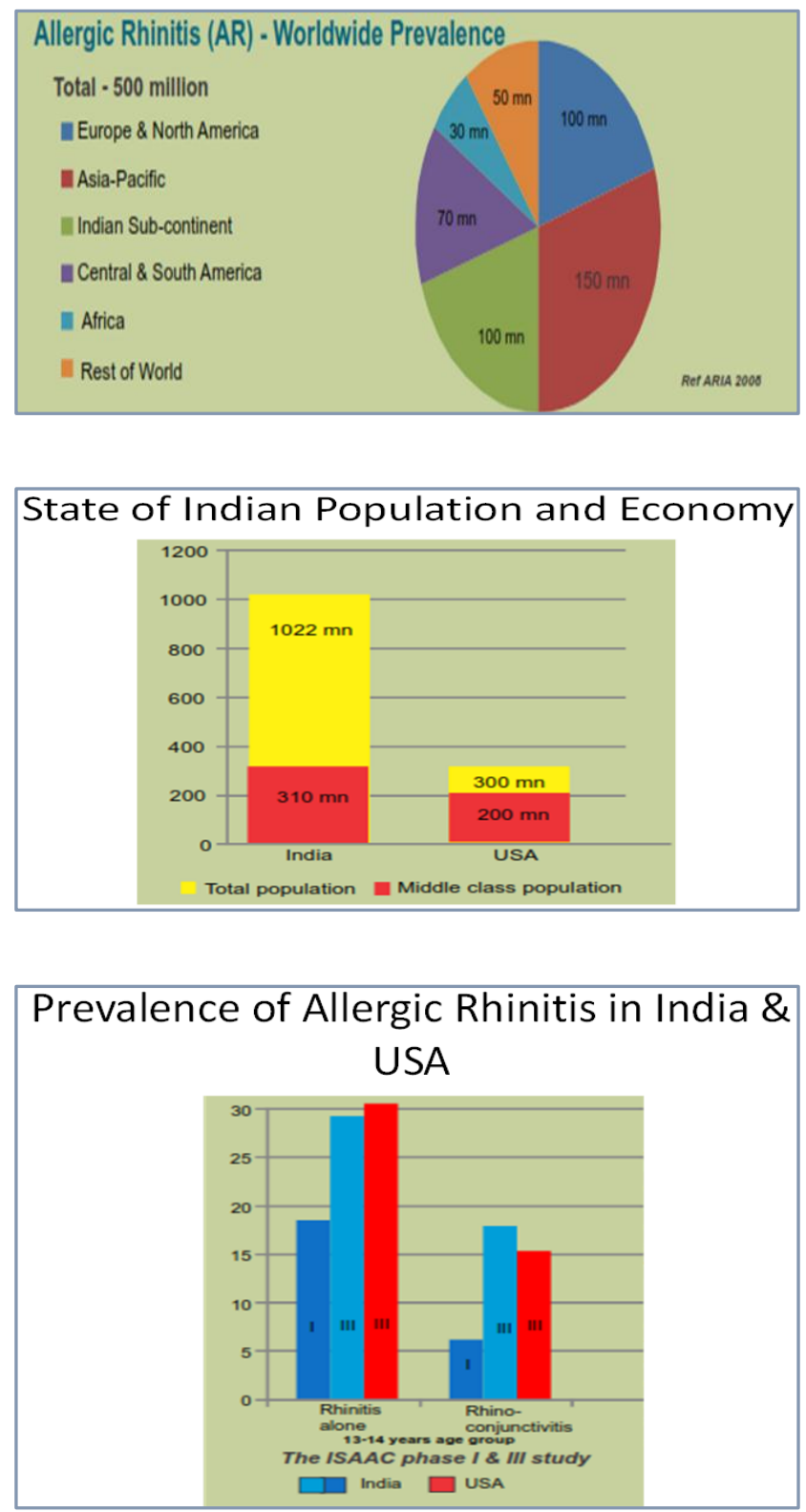
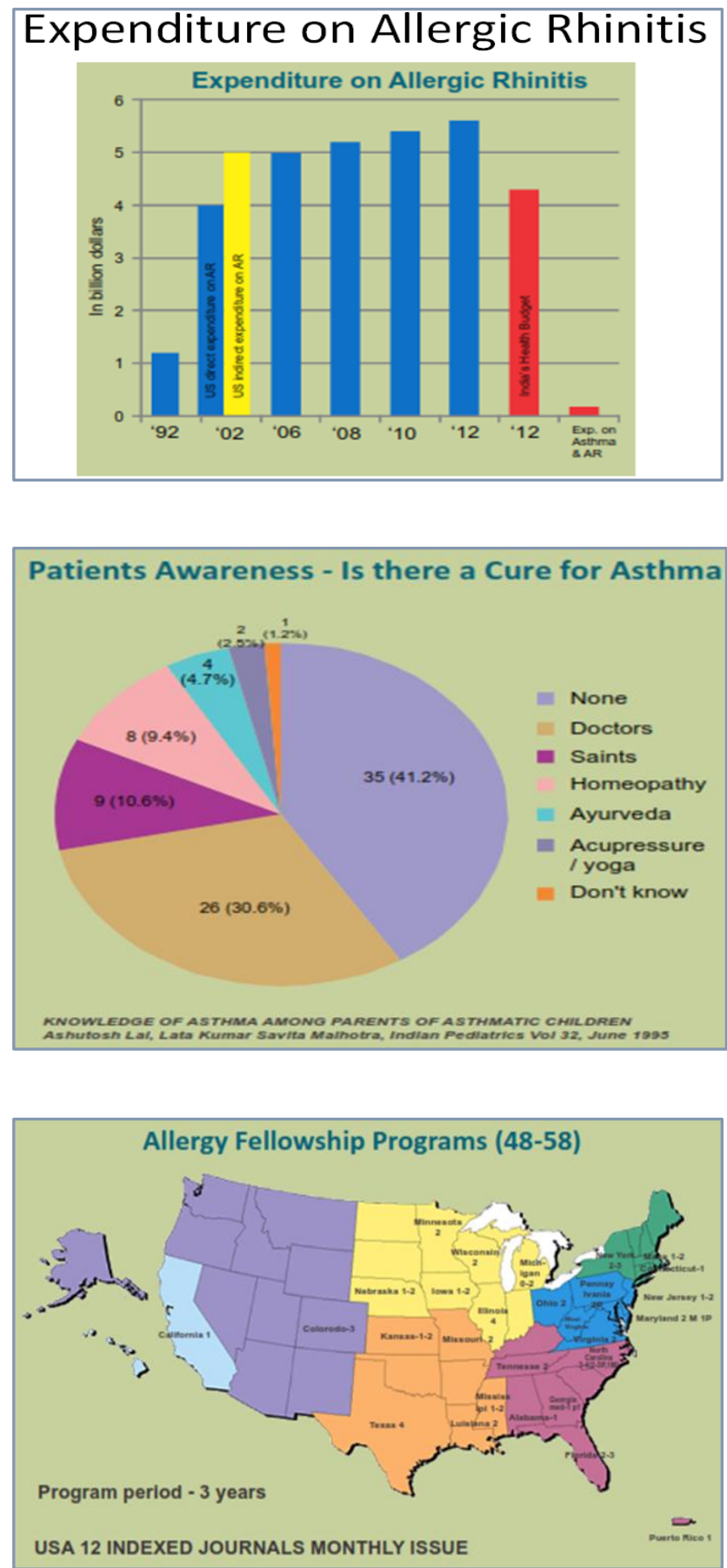

\section{DISCUSSIONS}

An analysis of the results reveals that although India has a huge population of 1250 million people, the middle class population is approximately 300 million equivalents to the population of USA. ${ }^{2}$ Since Allergy is a non-communicable lifestyle disorder present in the more affluent population.(3), it is natural that its prevalence would be the same in India. As per ARIA 2008, the prevalence of allergic rhinitis in South Asia is 100 million out of the world's total of 500 million. ${ }^{1}$

As per the ISAAC study, which is a benchmark for the prevalence of Allergic rhinitis, the results indicate that allergic rhinitis affects between $10 \%$ to $30 \%$ of all adults and as many as $40 \%$ of all children. ${ }^{6}$ Though studies show AR as widely prevalent in India, it is considered a trivial disease despite the fact that symptoms of rhinitis were present in $75 \%$ of children and $80 \%$ of all asthmatic adults. ${ }^{5}$ 
The total expenditure on AR in USA, both direct and indirect is almost 11 billion dollars. In comparative term, it is half the budget of the Indian army, the 2nd largest in the world ${ }^{8}$ The direct cost is 5.5 billion dollars equiv. to the health budget of the Government of India. And almost 30 times the expenditure in India on medications of AR and asthma.(7)

In such a disparate scenario, it is imperative to find whether there is over or under expenditure on the treatment or is it the lack of knowledge, education or poverty contributing to it. Since the purchasing power of the middle class is the same, poverty is less likely to be the cause.

Hence, education could be the culprit for the disparity and why we are less aware about Allergic Diseases as per the data shown below.

In the USA, there are 48 to 52 fellowship program of threeyear duration in allergy. Besides, there are 12 indexed allergy journals. In India, there are no indexed journals nor are there any Medical Council of India recognized programs in allergy. In a study by Lal et al published in Indian Paediatrics, $30.6 \%$ felt that there is a cure for asthma and $41.2 \%$ felt that there is no cure for asthma with a significant section feeling that it can be cured by alternative medicines and/or by saints. ${ }^{9}$

\section{CONCLUSIONS}

The quantum difference in the expenditure and available health care for AR in US raises questions whether the US is overspending on a disease causing mainly morbidity. However, the data revealed that a vast number of patients in India with AR are under-diagnosed and are suffering not only from the complications of the disease, but also have a poor Quality Of Life (QOL), Mitigation of which is the primary goal of therapy of AR. This can only be improved by awareness programs and post-graduate programs in allergic diseases.

\section{REFERENCES}

1. Bousquet J, Khaltaev N, Cruz AA, et al. Allergic rhinitis and its impact on asthma (ARIA). Allergy 2008;63(Suppl 86):160-8.

2. Homi Kharas. The emerging middle class in developing countries. OECD development centre, Working paper No. 285, Deutsche Bank Research 2010.

3. Duncan Graham-Rowe. Lifestyle: when allergies go west. Nature 2011;479:S2-S4.

4. Weiss KB, Sullivan SD. The health economics of asthma and rhinitis. I. Assessing the economic impact. Allergic rhinitis: indicators of quality of life. J Bras Pneumol 2010;36(1):124-33.

5. Settipane RA. Rhinitis: a dose of epidemiological reality. Allergy Asthma Proc 2003;24(3):147-54.

6. Shah A, Pawankar R. Allergic rhinitis and co-morbid asthma: perspective from India-ARIA Asia-Pacific workshop report. Asia Pac J Allergy Immunol 2009;27(1):71-7.

7. Sukumaran TU. Allergic rhinitis and co morbidities training module ARCTM. Indian Academy of Paediatrics 2011;48(7):511-3.

8. Laxman K Behera. India's defense budget 2012-2013. Institute for defense studies and analyses (IDSA) March 20 2012.

9. Ashutosh Lai, Lata Kumar, Savita Malhotra. Knowledge of asthma among parents of asthmatic children. Indian Paediatrics 1995;32(6):649-55. 